\title{
The effect of maternal smoking and ethanol on fatty acid transport by the human placenta
}

\author{
P. Haggarty ${ }^{1 *}$, D. R. Abramovich ${ }^{2}$ and K. Page ${ }^{3}$ \\ ${ }^{1}$ Rowett Research Institute, Aberdeen AB2 9SB, Scotland, UK \\ ${ }^{2}$ Department of Obstetrics and Gynaecology, Aberdeen University, Aberdeen AB9 2ZD, Scotland, UK \\ ${ }^{3}$ Department of Biomedical Sciences, Aberdeen University, Aberdeen AB9 2ZD, Scotland, UK
}

(Received 10 July 2000 - Revised 20 September 2001 - Accepted 20 November 2001)

\begin{abstract}
The role of the placenta in controlling the supply of fatty acids to the fetus was investigated in term placentas from non-smokers ( $n$ 5), smokers ( $>$ ten cigarettes/d; $n$ 5) and after addition of ethanol at $2 \mathrm{mg} / \mathrm{ml}(n 4)$. The maternal side was of the placenta was perfused ex vivo for $90 \mathrm{~min}$ with a physiological mixture of fatty acids and fatty acid:human albumin ratio. There was no effect of smoking on the transfer of linoleic (LA, 18:2 n-6), $\alpha$-linolenic $(\alpha \mathrm{LN}, 18: 3 n-3)$, arachidonic (AA, 20:4n-6) or docosahexaenoic acid (DHA, 22:6n-3), expressed per perfused area (calculated from $\mathrm{H}_{2}^{18} \mathrm{O}$ exchange). However, the presence of ethanol in the perfusate at a concentration of $2 \mathrm{mg} / \mathrm{ml}$ significantly reduced $(P<0 \cdot 01)$ the absolute rate of transfer of the two $n-3$ polyunsaturated fatty acids, $\alpha \mathrm{LN}$ and DHA. This specific effect of ethanol on $\alpha \mathrm{LN}$ and DHA also resulted in an altered selectivity for transfer of individual fatty acids. In the nonsmoking control group the placenta selectively transferred polyunsaturated fatty acids to the fetus in the order DHA $>\mathrm{AA}>\alpha \mathrm{LN}>\mathrm{LA}$. The order of selectivity was unaltered in placentas from smokers, but the addition of ethanol to the perfusion medium altered the order of selectivity to AA $>\alpha \mathrm{LN}>\mathrm{LA}>\mathrm{DHA}$. The presence of ethanol in the perfusate was also associated with a significant reduction $(P<0.05)$ in the clearance of $\mathrm{H}_{2}^{18} \mathrm{O}$. These results suggest that the presence of ethanol at a concentration of $2 \mathrm{mg} / \mathrm{ml}$ may reduce the availability of polyunsaturated fatty acids to the developing fetus.
\end{abstract}

Placenta: Smoking: Alcohol: Transport: Polyunsaturated fatty acids: Docosahexaenoic acid: Pregnancy

All of the $n-3$ and $n-6$ fatty acid structure acquired by the fetus has to cross the placenta, either in the form of the two essential fatty acids, linoleic (LA, 18:2 n-6) and $\alpha$ linolenic $(\alpha \mathrm{LN}, 18: 3 n-3)$, or their long-chain polyunsaturated fatty acid (PUFA) derivatives, of which arachidonic acid (AA, 20:4 n-6), eicosapentaenoic acid (EPA, 20:5 $n-3$ ) and docosahexaenoic acid (DHA, 22:6n-3) are metabolically the most important. Apart from their role in maintaining the fluidity, permeability and conformation of membranes, these fatty acids also play a critical role in metabolic control as precursors of the prostacyclins, prostaglandins, thromboxanes and leukotrienes. The ability of the placenta to extract $n-3$ and $n-6$ fatty acids from the maternal circulation and deliver them to the fetal circulation is therefore important for normal fetal development (Kuhn et al. 1985; Kuhn \& Crawford, 1986). Selectivity by the human placenta for the transport of individual fatty acids from the maternal to fetal circulation has been suggested as one mechanism that might explain the fact that the concentrations of some longchain PUFA are greater in the fetal than maternal circulation (Crawford et al. 1976; Hornstra et al. 1995; Crawford, 2000), a concept known as 'biomagnification' (Kuhn et al. 1985; Kuhn \& Crawford, 1986). In addition, it has been shown that the human placenta has the capacity to preferentially transfer the essential fatty acids and longchain PUFA (particularly DHA) from the maternal to fetal circulation (Haggarty et al. 1997, 1999).

Smoking during pregnancy has been reported to affect the morphology of the placenta and is associated with a reduction in birth weight (Ellard et al. 1996; Lindsay et al. 1997). Ethanol consumption during pregnancy has similarly been reported to reduce birth weight and placental weight (Larroque et al. 1993), although the

\footnotetext{
Abbreviations: AA, arachidonic acid; DHA, docosahexaenoic acid; LA, linoleic acid; $\alpha$ LN, $\alpha$-linolenic acid; PUFA, polyunsaturated fatty acids.

* Corresponding author: Dr Paul Haggarty, fax +44 1224 684880, email p.haggarty@abdn.ac.uk
} 
effect of ethanol on placental transport appears to differ for different nutrients and species. Hu et al. (1994) have shown that biotin uptake by basolateral membrane vesicles derived from human placenta is impaired by $10 \mathrm{~h}$ exposure to ethanol at concentrations of 2 and $3 \mathrm{mg} / \mathrm{ml}$ but not $1 \mathrm{mg} / \mathrm{ml}$. Studies in rats indicate that acute and chronic maternal ethanol consumption can depress the placental uptake of a variety of amino acids with the acute effect acting via a $\mathrm{Na}^{+}$-dependent system involved in amino acid influx into placental cells (Patwardhan et al. 1981; Henderson et al. 1982). The addition of ethanol to the perfused human placenta apparently has no effect on the in vitro transport of two amino acid analogues; $\alpha$-aminoisobutyric acid and cycloleucine; (Schenker et al. 1989), thiamine (Schenker et al. 1990), or Zn (Beer et al. 1992), but does affect lipid metabolism by increasing the endogenous production of triacylglycerol, non-esterified fatty acid and phospholipid by the perfused placenta when added at a concentration of $3 \mathrm{mg} / \mathrm{ml}$ (Rice et al. 1986).

Approximately $50 \%$ of the DM of the human brain consists of lipid and about half of this is made up of longchain PUFA (Gurr, 1993). Deposition of the long-chain PUFA in the fetus is rapid during the period of maximum brain growth in the last trimester (Clandinin et al. 1980) and it has been proposed that failure to accomplish a specific component of brain growth due to inadequacy of critical membrane lipids may result in irrevocable damage which cannot be fully restored at some later time and much attention has been given to the role of one long-chain PUFA in particular, DHA, in visual and intellectual development in children; see for example, Birch et al. (1992), Innis et al. (1996), Lucas et al. (1999). Ethanol consumption is known to affect the PUFA status of the brain, retina and liver (Salem \& Karanian, 1988; Pawlosky \& Salem, 1995) whilst fetal alcohol syndrome is the leading known cause of mental retardation (Bearer et al. 1992).

The purpose of the present study was to determine the effect of ethanol in the circulation or smoking during pregnancy on the capacity of the placenta to transport PUFA to the fetal circulation. There is no evidence that the placenta is intrinsically different after moderate alcohol exposure during pregnancy, but there is evidence of acute effects of moderate levels of alcohol on placental function and PUFA metabolism. Conversely, the reported effects of cigarette smoking on the placenta are largely in relation to morphological changes. Thus, the study was designed to investigate the acute effect of alcohol and the chronic effect of smoking since these are likely to be the most physiologically relevant. Specifically, we set out to determine the effect of smoking and ethanol on the order of selectivity and absolute placental transfer rates from the maternal to fetal circulation of the important PUFA (DHA, $\alpha \mathrm{LN}, \mathrm{LA}$ and AA) when the maternal face of the placenta was perfused with a physiological mixture of fatty acids and albumin (Haggarty et al. 1999).

\section{Materials and methods}

Ethical permission for the study was obtained from the Joint Ethical Committee of the Grampian Health Board and the University of Aberdeen and mothers taking part in the study gave informed consent. The fatty acid composition of red cells was measured, as described by Lakin et al. (1998), in twenty-four mothers (eleven smokers, thirteen non-smokers) with uncomplicated full-term pregnancies, and perfusion carried out in a subset of these $(n$ 14). To assess smoking frequency, a short multiple-choice questionnaire was used as this improves disclosure (Mullen et al. 1991). Only mothers who smoked ten or more cigarettes per $\mathrm{d}$ were included in the smoking group and the non-smokers did not smoke throughout pregnancy.

The perfusion experiments were conducted on term placentas delivered vaginally or by elective Caesarean section from otherwise uncomplicated pregnancies and the placentas were transferred to the perfusion chamber within $20 \mathrm{~min}$ of delivery. Both maternal and fetal circulations were perfused using the method described in detail elsewhere (Haggarty et al. 1997, 1999). The placental lobule was perfused with modified Krebs Ringer with the maternal perfusate being delivered at $20 \mathrm{ml} / \mathrm{min}$ by four glass cannulas inserted into the intervillous space and the outflow collected via a funnel placed under the lobule. The fetal perfusate $(7 \mathrm{ml} / \mathrm{min})$ was passed through a fine polythene cannula (i.d. $1.2 \mathrm{~mm}$ ) inserted into the artery supplying the lobule, the outflow being collected by a similar cannula placed in the lobular vein. The preparation was maintained between 37 and $38^{\circ} \mathrm{C}$. The solutions in both fetal and maternal circuits were oxygenated with $\mathrm{O}_{2}-\mathrm{CO}_{2}(95: 5, \mathrm{v} / \mathrm{v})$. Both the fetal and maternal circulation were open throughout the perfusion. The open-circuit design, where both perfusates pass through the placenta only once, was employed because a closed circuit design could potentially result in back transfer of labelled fatty acids from the fetal to maternal circulation and non-steady state with respect to the maternal fatty acid concentration and possibly specific activity, thereby complicating the interpretation of the isotopic data.

The lobule was initially perfused for $30 \mathrm{~min}$ with Krebs Ringer containing no fatty acid or albumin. Both circuits were then switched to Ringer containing fatty-acid-free human albumin ( $5 \mathrm{~g} / \mathrm{l}$; Sigma, Poole, Dorset, UK); in the ethanol studies this and all subsequent perfusates also contained ethanol at a concentration of $2 \mathrm{mg} / \mathrm{ml}$. After a further $30 \mathrm{~min}$, the fetal circuit was changed to Krebs Ringer containing $5 \mathrm{~g}$ fatty-acid-free human albumin/l and the maternal circuit to Krebs Ringer containing $5 \mathrm{~g}$ fattyacid-free human albumin/l and a mixture of radiolabelled (Du Pont, Stevenage, Herts., UK) and unlabelled fatty acids (Sigma) and $\mathrm{H}_{2}^{18} \mathrm{O}$ as a flow-limited marker. The albumin: free fatty acid molar ratio $(0.78)$ was kept the same as it was in vivo in human pregnancy (Friedman et al. 1978; Olufemi et al. 1991); concentration of albumin $5 \mathrm{~g} / \mathrm{l}$, fatty acid $87 \mu \mathrm{M}$; the proportionate fatty acid composition was designed to mimic the average fatty acid composition of the non-esterified fatty acid fraction from the fed and fasted blood samples collected from women in the last trimester of pregnancy $(\mathrm{g} / 100 \mathrm{~g}$ total fatty acids): palmitic 59.9, oleic 23.5, LA 6.9, $\alpha \mathrm{LN} 1 \cdot 3$, dihomo- $\gamma$-linolenic 1.0, AA $1 \cdot 9$, EPA 3.1, DHA $2 \cdot 3$ (Haggarty et al. 1999). The specific activity of the labelled fatty acids in the medium were $(\mathrm{kBq} / \mu \mathrm{mol}):\left[{ }^{14} \mathrm{C}\right] \mathrm{LA} 28,\left[{ }^{14} \mathrm{C}\right] \alpha \mathrm{LN} 162,\left[{ }^{14} \mathrm{C}\right] \mathrm{AA} 8$, $\left[{ }^{14} \mathrm{C}\right] \mathrm{DHA}$ 26. The fatty-acid-free albumin was dissolved 
in the maternal and fetal perfusates. The labelled fatty acid mixture was taken up in a small volume of ethanol and added to the maternal perfusate and the mixture allowed to equilibrate overnight to allow the fatty acids to bind to albumin. The final concentration of ethanol in the maternal perfusates after addition of fatty acids was $0 \cdot 1-0.2 \mathrm{mg} / \mathrm{ml}$. In the perfusions designed to determine the effect of ethanol on placental fatty acid transport ethanol was added to increase the concentration by $2 \mathrm{mg} / \mathrm{ml}$.

All the measurements were carried out under steady state as previously described (Haggarty et al. 1997). The perfusate was collected from the maternal and fetal circuits over 15 min periods and stored frozen until analysed. The pooled maternal and fetal perfusates were acidified to $\mathrm{pH}$ 3.0 and lipids extracted (Bligh \& Dyer, 1959). After methylation the fatty acids were isolated by reverse-phase HPLC on a Rainin Dynamax ${ }^{\circledR}$ Microsorb $^{\text {TM }} 4.6 \times 250 \mathrm{~mm}$ column packed with $5 \mu \mathrm{m}$ particle size $\mathrm{C}_{18}$ (Rainin Instrument Co. Inc., Woburn, MA, USA) and protected by a $\mathrm{C}_{18}$ guard column (Upchurch Scientific, Oak Harbor, WA, USA). Peaks were detected using a Waters 490E multiwavelength UV-Vis detector set (Waters, Elstree, Hertford, UK) at $198 \mathrm{~nm}$ and samples collected by a Gilson model 201 fraction collector (Gilson Medical Electonics S.A, Villiers-le-Bel, France). The solvents used were HPLC grade 'Far UV' acetonitrile (BDH Merck Ltd, Poole, UK) and $30 \mathrm{mM}$ orthophosphoric acid (BDH Merck Ltd), both filtered through $0.45 \mu \mathrm{m}$ nylon filters (Watman International, Maidstone, Kent, UK) and degassed with $\mathrm{CP}$ grade $\mathrm{He}$ (BOC Ltd, Manchester, UK). Fractions were collected every $2 \mathrm{~min}$ and the radioactivity determined by liquid scintillation counting on a Canberra-Packard 1900CA liquid scintillation counter (Packard Instruments B.V., Groningen, The Netherlands). The $\mathrm{H}_{2}^{18} \mathrm{O}$ concentration in the maternal and fetal perfusates was determined after equilibration with $\mathrm{CO}_{2}$ (Midwood et al. 1992) on a SIRA-12 isotope ratio MS (VG, Middlewich, Ches., UK) relative to a series of laboratory reference waters previously calibrated against international standards.

An index of the perfused area in each experiment was derived from the clearance of $\mathrm{H}_{2}^{18} \mathrm{O}(\mathrm{ml} / \mathrm{min})$ added to the maternal circulation, and the absolute rates of fatty acid transfer expressed relative to $\mathrm{H}_{2}^{18} \mathrm{O}$ clearance $(\mathrm{nmol} / \mathrm{ml})$. Clearance $\left(\mathrm{ml} / \mathrm{min}\right.$ ) of the $\mathrm{H}_{2}^{18} \mathrm{O}$ from the maternal to fetal circulation was calculated from the arterial and venous fetal concentration difference, the maternal concentration and the fetal flow rate $(\mathrm{ml} / \mathrm{min})$ :

(fetal arterial concentration

- fetal venous concentration)

$$
\text { Clearance }=\frac{\times \text { fetal flow rate }}{\text { maternal concentration }} .
$$

Clearance of the individual fatty acids was similarly calculated using the arterial and venous fetal concentration difference, the maternal concentration and the fetal flow rate. The selectivity for individual fatty acids was assessed by expressing the clearance rate of $\alpha \mathrm{LN}, \mathrm{AA}$ and DHA relative to LA (Haggarty et al. 1997).

The significance of differences between the means was

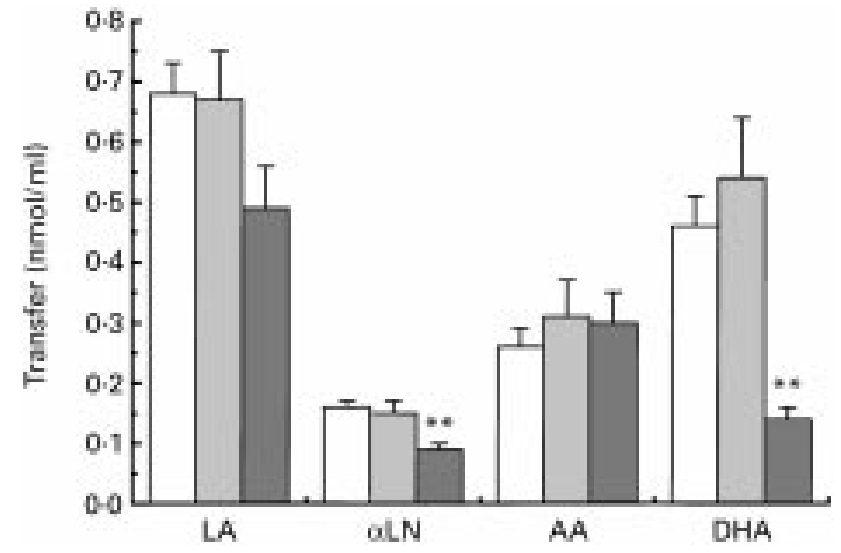

Fig. 1. Comparison of absolute placental transfer rates, normalised for perfused areas in exchange, $(\mathrm{nmol} / \mathrm{ml})$ of linoleic acid (LA), $\alpha$-linolenic $(\alpha \mathrm{LN})$, arachidonic $(A A)$ and docosahexaenoic acid $(\mathrm{DHA})$, in placentas from non-smokers $(n 5)$, smokers $(n 5)$ and in control placentas $(n 4)$ after addition of ethanol to the perfusate at a concentration of $2 \mathrm{mg} / \mathrm{ml}$. For details of procedures, see p. 248. $\square$, Control; $\square$, smoking; $\square$, alcohol. Values are means with standard errors shown by vertical bars. Mean values were significantly different from those of the control group: ${ }^{* *} P<0.01$.

calculated by two-tailed $t$ test (Minitab Inc., Philadelphia, PA, USA).

\section{Results}

The rates of transfer of the $n-6$ fatty acids, LA and AA, per perfused area (calculated from $\mathrm{H}_{2}^{18} \mathrm{O}$ exchange) were not different between the control, smokers and ethanol group (Fig. 1). Neither was the rate of placental transfer of $\alpha \mathrm{LN}$ and DHA affected by smoking during pregnancy. However, the presence of ethanol in the perfusate at a

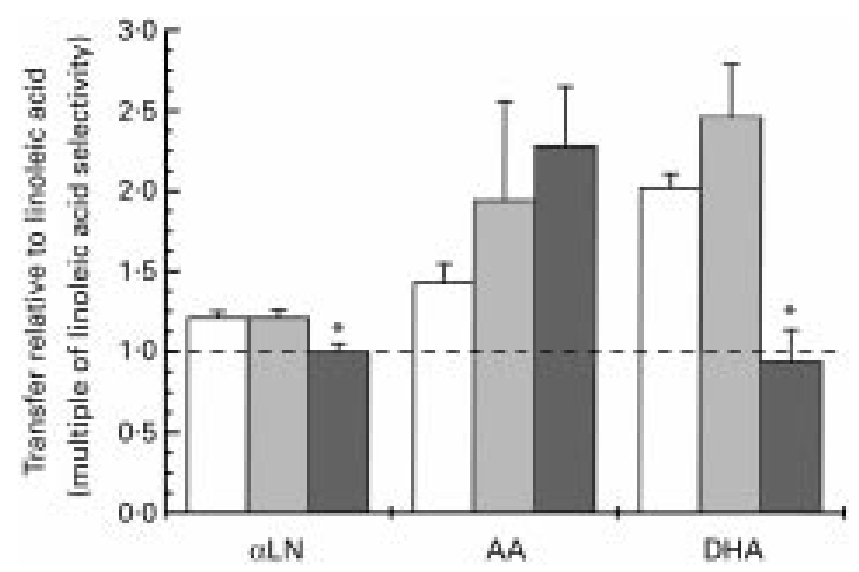

Fig. 2. Comparison of selectivity for placental transfer of $\alpha$-linolenic $(\alpha \mathrm{LN})$, arachidonic (AA) and docosahexaenoic acid (DHA), expressed as a proportion of that for linoleic acid (LA), taken as unity $(----)$, in placentas from non-smokers $(n 5)$, smokers $(n 5)$ and in control placentas ( $n$ 4) after addition of alcohol to the perfusate at a concentration of $2 \mathrm{mg} / \mathrm{ml}$. For details of procedures, see p. 248. $\square$, Control; $\square$, smoking; $\square$, alcohol. Values are means with standard errors shown by vertical bars. Mean values were significantly different from those of control group: ${ }^{*} P<0.05$. 


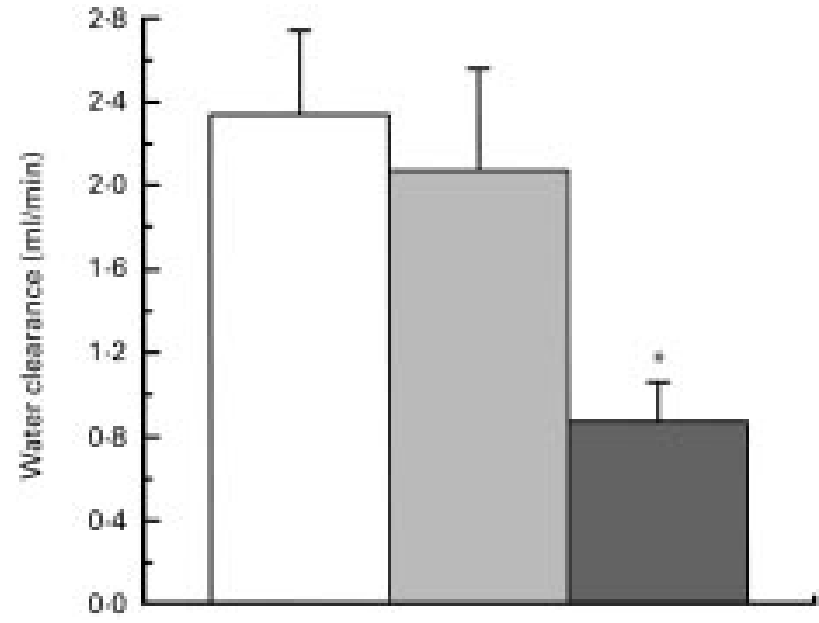

Fig. 3. Comparison of water clearance rates as measured with $\mathrm{H}_{2}^{18} \mathrm{O}$ in placentas from non-smokers $(n 5)$, smokers $(n 5)$ and after the addition of alcohol to the perfusate at a concentration of $2 \mathrm{mg} / \mathrm{ml}(n 4)$. For details of procedures, see p. 248. $\square$, Control; $\square$, smoking; $\square$, alcohol. Values are means with standard errors shown by vertical bars. Mean values was significantly different from those of the control group: ${ }^{*} P<0.05$.

concentration of $2 \mathrm{mg} / \mathrm{ml}$ significantly reduced $(P<0 \cdot 01)$ the absolute rate of transfer of the two $n-3$ PUFA, $\alpha \mathrm{LN}$ and DHA. The addition of ethanol resulted in an increase in the absolute rate of transfer of $\mathrm{AA}$ and a $60 \%$ increase in selectivity for this fatty acid over LA (Fig. 2), but this effect was not significant. However, the specific effect of ethanol on the $n-3$ fatty acids resulted in a significantly altered selectivity for transfer $(P<0 \cdot 05)$. When the placenta was perfused with fatty acids in the ratios found in maternal circulating non-esterified fatty acids, the placenta selectively transferred PUFA to the fetus in the order DHA $>$ AA $>\alpha$ LN $>$ LA. The order of selectivity was unaltered in placentas from smokers but the addition of ethanol to the perfusion medium had a large enough effect on DHA to alter the order of selectivity to AA $>\alpha \mathrm{LN}>$ LA $>$ DHA. Apart from an effect on transfer which was apparently specific to the $n-3$ fatty acids the presence of ethanol in the perfusate was associated with a significant reduction $(P<0 \cdot 05)$ in the clearance of $\mathrm{H}_{2}^{18} \mathrm{O}$ (Fig. 3).

The fatty acid composition of red blood cells may be taken as a broad indication of the availability of individual PUFA in the fetal circulation over a period of weeks. Apart from a small difference between the smokers and nonsmokers in the maternal red blood cell fatty acid concentration of 16:1 (0.50 (SD 0.14) v. 0.67 (SD 0.11) \% respectively), there were no significant differences between the two groups in either the maternal composition, the cord blood composition or the difference between the maternal and cord blood composition (results not shown).

\section{Discussion}

During most of pregnancy the fetus does not have a significant store of fatty acids such as DHA and is therefore dependent on a continuous supply of these fatty acids from the placenta to support development. Anything which interrupts this supply during the relatively narrow time frames within which the key structures in the brain and retina are formed may have significant functional consequences. The purpose of the present study was to determine whether smoking and alcohol consumption during pregnancy could alter the capacity of the placenta to transport important PUFA to the fetal circulation. The perfusion results suggest that smoking during pregnancy has no effect on either the total placental transfer per perfused area or the selectivity for individual fatty acids and therefore that the previously described alterations in placental morphology in smokers appear to have no effect on fatty acid transport function. It is still possible that placental fatty acid transport may be impaired in vivo due to the effect of nicotine and the other components of cigarette smoke on placental blood flow for example. However, there were no significant differences between smokers and non-smokers in the fatty acid composition of maternal and cord red blood cells or in the percent difference between maternal and cord blood fatty acids. These results support the conclusions from the perfusion data that the placental supply of fatty acid to the fetus is likely to be unaffected in mothers who smoke during pregnancy.

The alcohol concentration of $2 \mathrm{mg} / \mathrm{ml}$ chosen for these present studies represents a compromise: it is the lowest level at which effects on placental transport had previously been reported for other nutrients (Hu et al. 1994) and lower than that previously shown to produce changes in placental export of lipid classes (Rice et al. 1986), and whilst it would represent a significant intake of alcohol (2.5-fold the legal limit for driving in the UK) people do drink to such levels of intoxication. When placentas were perfused with ethanol at this concentration, there was no significant alteration in AA transfer to the fetal circulation per perfused area but there was a reduction in the transfer of LA, $\alpha$ LN and DHA and this effect was significant for the two $n-3$ fatty acids with the transfer of DHA in particular being reduced to a third of that found in control placentas. The selective alteration in the transfer of individual fatty acids resulted in a change in the order of selectivity from $\mathrm{DHA}>\mathrm{AA}>\alpha \mathrm{LN}>\mathrm{LA}$ in the control placentas to $\mathrm{AA}>\alpha \mathrm{LN}>\mathrm{LA}>\mathrm{DHA}$ in the presence of ethanol. The observed hierarchy of fatty acid transfer to the fetal circulation may arise for several reasons: (1) selective uptake by the syncitiotrophoblast; (2) different metabolic fates for individual fatty acids within the cell; and (3) differential release into the fetal circulation of fatty acids available within the cell. The available evidence indicates that selectivity for individual fatty acids operates both at the level of placental uptake (Campbell et al. 1996; Haggarty et al. 1999) and placental metabolism (Haggarty et al. 1997) and one or both of these may be affected by the presence of ethanol. Campbell et al. (1996) have reported preferential binding of fatty acids by isolated human placental membranes in the order $\mathrm{AA}>\mathrm{LA}>\alpha \mathrm{LN}>$ oleic and have proposed that such differential binding is mediated by a specific placental membrane fatty acid binding protein. It is worth noting that the order of selective transfer in the control placentas was similar to the order of double bond number (in parentheses) in these 
molecules: DHA (6) $>$ AA (4) $>\alpha \mathrm{LN} \quad$ (3) $>$ LA (2); therefore, the physico-chemical properties conferred by the number of double bonds may influence the preference for fatty acid transfer via the physical interaction of fatty acids with cell membranes and/or binding proteins. Ethanol may have a direct effect on the binding properties of fatty acid binding proteins, perhaps related to the $n$-terminus double-bond position, since the effect of ethanol was only significant for the two n-3 PUFA.

There is a report of a significant increase in the concentration of DHA in one of the minor lipid fractions (cholesterol ester) of cord serum from women who consumed alcohol during pregnancy but no difference in the other fractions (Denkins et al. 2000). However, such data provide only a broad indication of supply as levels of fatty acids in the blood, and the plasma and/or serum in particular, are affected by many factors in addition to placental transfer. Denkins et al. (2000) observed that alcohol intake in their study group was greatly diminished in the weeks before birth and they refer to animal studies showing unchanged or elevated DHA concentrations in the plasma but significant reductions in the DHA content of the brain of fetuses whose mothers were exposed to ethanol during gestation (Burdge \& Postle, 1995; Denkins et al. 2000). Because of these issues, it is necessary to use perfusion or similar techniques to determine whether the difference in brain lipids is likely to be due to a limitation to transfer or some alteration in fatty acid metabolism within the fetal brain.

Ethanol consumption is known to affect the metabolism of PUFA and their concentrations in tissues such as the brain, retina and liver (Salem \& Karanian, 1988; Pawlosky \& Salem, 1995) via its effects on chain elongation and desaturation, and conversion to other metabolites such as prostaglandins and fatty acid ethyl esters (Cunnane, 1987; Laposata et al. 1987). The placenta is an important site of production of the prostacyclins, prostaglandins, thromboxanes and leukotrienes and it has been shown that ethanol addition to the perfused human placenta results in the production of prostaglandin E (Laposata et al. 1987; Randall et al. 1996). However, prostaglandin E is produced from AA, the placental transfer of which was actually increased by the addition of ethanol although not significantly so. Conversely, if the specific effect of ethanol on $\alpha \mathrm{LN}$ and DHA were to operate via prostaglandin production these would first have to be converted to eicosapentaenoic acid by chain elongation and desaturation and retroconversion respectively and there is little evidence for the former in the human placenta (Haggarty et al. 1997). Thus, although ethanol has been shown to alter prostaglandin production from PUFA within the placenta, the effect of ethanol on $\alpha \mathrm{LN}$ and DHA transfer may operate through some other mechanism, e.g. selective oxidation or esterification within the placenta, although it is possible that these other metabolic transformations may be influenced by the effect of ethanol on prostaglandins production. It is known, for example, that ethanol increases the endogenous production of lactate, triacylglycerol, free fatty acids and phospholipids by the perfused placenta (Rice et al. 1986), suggesting a direct effect on intracellular metabolism within the placenta.
The observed reduction in placental exchange area after addition of ethanol is consistent with previous studies showing that alcohol administration in vivo reduces placental blood flow in sheep (Falconer, 1990) and induces a dose-dependent vasoconstriction in the concentration range of $0.01-3.00 \mathrm{mg} / \mathrm{ml}$ in vitro in the perfused human placenta (Taylor et al. 1994). The vasoconstriction resulting from ethanol addition to the perfused human placenta may also be linked to fatty acid metabolism via its effect on prostaglandin production since the pressor effect of ethanol is largely removed by the presence of the COX inhibitor indomethacin (Taylor et al. 1994). Whatever the mechanism, it appears that ethanol results in a selective reduction in placental transfer to the fetal circulation of both $\alpha \mathrm{LN}$ and DHA. When this effect is combined with the reduction in blood flow to the placenta associated with the presence of ethanol, then it is apparent that there will be a reduction in the fetal availability of all the PUFA at an ethanol concentration of $2 \mathrm{mg} / \mathrm{ml}$. The effect will be most pronounced for DHA, which is important for the normal development of the fetal brain and retina. Fetal alcohol syndrome can occur at lower concentrations of ethanol than the $2 \mathrm{mg} / \mathrm{ml}$ used here, therefore the relevance of the selective reduction in DHA transfer in particular to all cases of this syndrome would have to be confirmed in perfusion studies at lower concentrations. However, the previously reported dose-dependent vasoconstriction in the human placenta at much lower alcohol concentrations than $2 \mathrm{mg} / \mathrm{ml}$ (Rice et al. 1986) would in itself reduce placental transport of all the PUFA, including DHA, via its effect on placental blood flow.

\section{Acknowledgement}

This research was supported by The Scottish Office Rural Affairs Department.

\section{References}

Bearer CF, Gould S, Emerson R, Kinnunen P \& Cook CS (1992) Fetal alcohol syndrome and fatty-acid ethyl-esters. Pediatric Research 31, 492-495.

Beer WH, Johnson RF, Guentzel MN, Lozano J, Henderson GI \& Schenker S (1992) Human placental transfer of zinc: Normal characteristics and role of ethanol. Alcoholism, Clinical and Experimental Research 16, 98-105.

Birch EE, Birch DG, Hoffman DR \& Uauy R (1992) Dietary essential fatty-acid supply and visual-acuity development. Investigative Ophthalmology and Visual Science 33, 3242-3253.

Bligh EG \& Dyer WJ (1959) A rapid method of total lipid extraction and purification. Canadian Journal of Biochemistry and Physiology 37, 911-917.

Burdge GC \& Postle AD (1995) Effect of maternal ethanol consumption during pregnancy on the phospholipid molecular species composition of fetal guinea-pig brain, liver and plasma. Biochimica et Biophysica Acta 1256, 346-352.

Campbell FM, Gordon MJ \& DuttaRoy AK (1996) Preferential uptake of long chain polyunsaturated fatty acids by isolated human placental membranes. Molecular and Cellular Biochemistry 155, 77-83.

Clandinin MT, Chappell JE \& Leong S (1980) Intrauterine fatty 
acid accretion rates in human brain: Implications for fatty acid requirements. Early Human Development 4, 131-138.

Crawford M (2000) Placental delivery of arachidonic and docosahexaenoic acids: implications for the lipid nutrition of preterm infants. American Journal of Clinical Nutrition 71, 275S-284S.

Crawford MA, Hassam AG, Williams SCR \& Whitehouse WL (1976) Essential fatty acids and fetal brain growth. Lancet $\mathbf{i}$, 452-453.

Cunnane SC (1987) Hepatic triacylglycerol accumulation induced by ethanol and carbon-tetrachloride - interactions with essential fatty-acids and prostaglandins. Alcoholism - Clinical and Experimental Research 11, 25-31.

Denkins YM, Woods J, Whitty JE, Hannigan JH, Martier SS, Sokol RJ \& Salem N Jr (2000) Effects of gestational alcohol exposure on the fatty acid composition of umbilical cord serum in humans. American Journal of Clinical Nutrition 71, 300S-306S.

Ellard GA, Johnstone FD, Prescott RJ, Wang JX \& Mao JH (1996) Smoking during pregnancy: The dose dependence of birthweight deficits. British Journal of Obstetrics and Gynaecology 103, 806-813.

Falconer J (1990) The effect of maternal ethanol infusion on placental blood-flow and fetal glucose-metabolism in sheep. Alcohol and Alcoholism 25, 413-416.

Friedman Z, Danon A, Lamberth EL \& Mann WJ (1978) Cord blood fatty acid composition in infants and their mothers during the third trimester. Journal of Pediatrics 92, 461-466.

Gurr M (1993) Fats. In Human Nutrition and Dietetics, pp. 77-102 [JS Garrow and WPT James, editors]. Edinburgh: Churchill Livingstone.

Haggarty P, Ashton J, Joynson M, Abramovich DR \& Page K (1999) Effect of maternal polyunsaturated fatty acid concentration on transport by the human placenta. Biology of the Neonate 75, 350-359.

Haggarty P, Page K, Abramovich DR, Ashton J \& Brown D (1997) Long-chain polyunsaturated fatty acid transport across the perfused human placenta. Placenta 18, 635-642.

Henderson GI, Patwardhan RV, McLeroy S \& Schenker S (1982) Inhibition of placental amino acid uptake in rats following acute and chronic ethanol exposure. Alcoholism, Clinical and Experimental Research 6, 495-505.

Hornstra G, Al MDM, Houwelingen AC \& Foreman Van Drongelen MMHP (1995) Essential fatty acids in pregnancy and early human development. European Journal of Obstetrics Gynaecology and Reproduction 61, 57-62.

Hu Z-Q, Henderson GI, Mock DM \& Schenker S (1994) Biotin uptake by basolateral membrane vesicles of human placenta: Normal characteristics and role of ethanol. Proceedings of the Society for Experimental Biology and Medicine 206, 404-408.

Innis SM, Nelson CM, Lwanga D, Rioux FM \& Waslen P (1996) Feeding formula without arachidonic acid and docosahexaenoic acid has no effect on preferential looking acuity or recognition memory in healthy full-term infants at 9 months of age. American Journal of Clinical Nutrition 64, 40-46.

Kuhn DC \& Crawford M (1986) Placental essential fatty acid transport and prostaglandin synthesis. Progress in Lipid Research 25, 345-353.

Kuhn DC, Crawford MA \& Stevens P (1985) Transport and metabolism of essential fatty acids by the human placenta. Contributions to Gynecology and Obstetrics 13, 139-140.

Laposata EA, Scherrer DE, Mazow C \& Lange LG (1987) Metabolism of ethanol by human-brain to fatty-acid ethylesters. Journal of Biological Chemistry 262, 4653-4657.

Larroque B, Kaminski M, Lelong N, Subtil D \& Dehaene P (1993) Effects on birth weight of alcohol and caffeine consumption during pregnancy. American Journal of Epidemiology 137, 941-950.

Lindsay CA, Thomas AJ \& Catalano PM (1997) The effect of smoking tobacco on neonatal body composition. American Journal of Obstetrics and Gynecology 177, 1124-1128.

Lucas A, Stafford M, Morley R, Abbott R, Stephenson T, MacFadyen U, Elias-Jones A \& Clements H (1999) Efficacy and safety of long-chain polyunsaturated fatty acid supplementation of infant-formula milk: a randomised trial. Lancet 354, 1948-1954.

Midwood AJ, Haggarty P, Milne E \& McGaw BA (1992) Factors affecting the analysis of O-18-enriched aqueous samples when using $\mathrm{CO}_{2}$ equilibration in vacutainers. Applied Radiation and Isotopes 43, 1341-1347.

Mullen PD, Carbonari JP, Tabak ER \& Glenday MC (1991) Improving disclosure of smoking by pregnant-women. American Journal of Obstetrics and Gynecology 165, 409-413.

Olufemi OS, Whittaker PG, Halliday D \& Lind T (1991) Albumin metabolism in fasted subjects during late pregnancy. Clinical Science 81, 161-168.

Patwardhan RV, Schenker S, Henderson GI, Abou-Mourad NN \& Hoyumpa AM (1981) Short-term and long-term ethanol administration inhibits the placental uptake and transport of valine in rats. Journal of Laboratory and Clinical Medicine $\mathbf{9 8 ,}$ 251-262.

Pawlosky RJ \& Salem N (1995) Ethanol exposure causes a decrease in docosahexaenoic acid and an increase in docosapentaenoic acid in feline brains and retinas. American Journal of Clinical Nutrition 61, 1284-1289.

Randall CL, Ekblad U, White NM \& Cook JL (1996) Increase in vasoactive prostaglandin $\mathrm{E}$ production after ethanol perfusion in human placental cotyledons. Alcoholism - Clinical and Experimental Research 20, 1321-1328.

Rice PA, Nesbitt REL, Cuenca VG, Zhang W, Gordon GB \& Kim TJ (1986) The effect of ethanol on the production of lactate, triglycerides, phospholipids, and free fatty-acids in the perfused human-placenta. American Journal of Obstetrics and Gynecology 155, 207-211.

Salem NJ \& Karanian JW (1988) Polyunsaturated fatty acids and ethanol. Advances in Alcohol and Substance Abuse 7, 183-197.

Schenker S, Johnson RF, Hays SE, Ganeshappa R \& Henderson GI (1989) Effects of nicotine and nicotine/ethanol on human placental amino acids transfer. Alcohol 6, 289-296.

Schenker S, Johnson RF, Hoyumpa AM \& Henderson GI (1990) Thiamine-transfer by human placenta: Normal transport and effects of ethanol. Journal of Laboratory and Clinical Medicine 116, 106-115.

Taylor SM, Heron AE, Cannell GR \& Florin THJ (1994) Presser effect of ethanol in the isolated-perfused human placental lobule. European Journal of Pharmacology - Environmental Toxicology and Pharmacology Section 270, 371-374. 